\title{
Mechanical And Thermal Behavior of Carbon Nanotubes/ Vinyl Ester Nanocomposites
}

\author{
ADRIAN COTEȚ ${ }^{1}$, MARIAN BAŞTIUREA ${ }^{1}$, GABRIEL ANDREI $^{1 *}$, ALINA CANTARAGIU $^{1}$, ANTON HADĂR ${ }^{2,3,4}$ \\ ${ }^{1}$ Dunărea de Jos University of Galaţi, Faculty of Engineering, 47 Domneasca Str., Galati, 800008, Romania \\ ${ }^{2}$ University Politehnica of Bucharest, Department of Materials Strength, Splaiul Independenţei 313, Bucharest, 060042, Romania \\ ${ }^{3}$ Academy of Romanian Scientists, 3 Ilfov Str., Bucharest, 050045, Romania \\ ${ }^{4}$ Technical Sciences Academy of Romania, 26 Dacia Blvd, Bucharest, 010413, Romania
}

Single walled carbon nanotubes (SWCNT) and multi walled carbon nanotubes (MWCNT)/vinyl ester nanocomposites with three different contents of carbon nanotubes (CNTs) have been prepared by the simple melt-compounding method. A fine and homogeneous dispersion of CNTs throughout vinyl ester resin has been noticed by SEM images. Two mechanical tests (compression and three point bending test) show that, compared to neat vinyl ester resin, compression modulus and compression strength of the nanocomposites have been significantly improved by about $9 \%$ and $14 \%$, respectively, when incorporating only $0.15 \mathrm{wt} \%$ MWCNTs. Furthermore, thermal behavior of SWCNT and MWCNT/ vinyl ester nanocomposites has been investigated and discussed based on differential scanning calorimetry (DSC) and thermomechanical analysis (TMA). Glass transition temperature (Tg) and coefficient of thermal expansion (CTE) have been increased and decreased, respectively, with increasing of CNTs content.

Keywords: vinyl ester, carbon nanotubes, compression, bending, thermal test

Vinyl ester resins are currently used as thermoset matrix to manufacture a wide range of products including gear, cell phones accessories, floor lining, waterproofing rooftop, motorcycles helmets, ducts. Vinyl esters are used in a growing number of applications in civil engineering, structural applications, coatings, molding compounds. Compared to polyester and epoxy resin, vinyl ester shows better chemical resistance, good control of curing rate and reaction conditions. Flexural modulus values in the range of 2...3.2 GPa, and flexural stress between 90 and $129 \mathrm{MPa}$ have been obtained in case of neat vinyl ester submitted to three point bending test [1-3]. The flexural stress of vinyl ester depends on the curing temperature, such that decreasing the curing temperature from $110^{\circ} \mathrm{C}$ to $80^{\circ}$ or $90^{\circ} \mathrm{C}$, lead to an increasing flexural stress with $15 \%$ and $20 \%$ [4]. The influence of curing regime on mechanical properties was explained by that curing reactions led to increasing viscosity, due to formation of microgels [5, 6]. Mechanical properties of vinyl ester such as flexural strength, compression strength and modulus, depends on curing temperature and may be improved by addition of different additive. It is also known the good compatibility between vinyl ester resin and glass fibers [7,8] or clay [9-17] and their beneficial effect on the mechanical properties of the vinyl ester composites.

DSC was used to determine specific heat and glass transition temperature of vinyl ester resin. It has been found that glass transition temperature depends on styrene content, and a temperature range between $131^{\circ} \mathrm{C} \mathrm{o} 151{ }^{\circ} \mathrm{C}$ has been found for styrene content between 30\%-50\% [18]. Also, the curing temperature has influence on glass transition temperature. In case of curing at room temperature, glass transition temperature was found to be $60^{\circ}$ or $70^{\circ} \mathrm{C}$.

When curing temperature was $120^{\circ}$, then $\mathrm{Tg}$ was $82^{\circ} \mathrm{C}$ [19]. Increasing the curing temperature up to $150^{\circ} \mathrm{C}$, the glass transition temperature was $95^{\circ} \mathrm{C}$ [20]. In order to improve the thermal properties, glass flakes [21-23], clay [13-15], and glass fibers [24-27] have been introduced into vinyl ester resin.

Carbon nanotubes, an allotropic form of carbon, have been investigated as a reinforcement material in polymer composites by virtue of their excellent mechanical and thermal properties. Depending on the method used to determine the mechanical properties of carbon nanotubes, there is a wide range of flexural stress from $11 \mathrm{GPa}$ to $63 \mathrm{GPa}[28,29]$, and a range of flexural modulus between $600 \mathrm{GPa}$ to $1,1 \mathrm{TPa}$ [30-35]. In order to use such properties, various polymers have been mixed with carbon nanotubes to obtain polymer nanocomposites with better mechanical and thermal properties. Several experimental investigations have proved that a good interface between CNTs and polymer matrix may improve mechanical and electrical properties of the polymer composites [36-38].

\footnotetext{
*email: gabriel.andrei@ugal.ro, Phone:0722266825
} 
MWCNT was used as additive for vinyl ester composites in order to increase flexural stress with 48\% [39], 24\% [40] or $29 \%$ [41] compared to neat resin. Aligned MWCNs were used to study the influence on glass transition temperature. Depending on the orientation of nanotubes, the glass transition temperature increased from $93^{\circ} \mathrm{C}$, for neat vinyl ester, to $107^{\circ} \mathrm{C}$ for aligned nanotube with DC electric field $[42,43]$.

In the present article, the mechanical (bending and compression) and thermal properties (DSC and TMA) of neat vinyl ester and its nanocomposites have been investigated.

Also, the effect of the addition of carbon nanotube into the vinyl ester matrix on the overall properties of nanocomposites has been discussed, considering the serious drawback in obtaining a good dispersion of nanoparticles into polymer matrix that is the natural tendency of the carbon nanotubes to agglomerate $[44,45]$.

\section{Experimental part}

Materials and methods

Vinyl ester resin POLIMAL VE 11M was supplied by SC PROFESIONAL SRL and was used as such. According to the quality certificate provided by the supplier, the bending stress for vinyl, as per ISO 178, was $120 \mathrm{MPa}$. The composite specimens studied in this work were prepared by reinforcing vinyl ester resin with multiwall and single wall CNTs. The amount of MWCNTs and SWCNTs in the composite has been set to $1.0 \mathrm{wt} \%, 0.15 \% \mathrm{wt}$ and $0.2 \%$ wt. In order to obtain SWCNT/ vinyl ester (SW) and MWCNT/ vinyl ester (MW) nanocomposites respectively, a certain amount of carbon nanotubes was introduced into resin using the analytical balance Kern, model EG4200 - 2 NM, precision 0,001g. The mixture was placed in a mortar and stirred for $1 \mathrm{~h}$ using a magnetic stirrer $(600 \mathrm{rpm})$. Afterwards, the mixture was degassed under vacuum (1-2 torr) for 1 minute. The catalyst, $1 \%$ cobalt octoate was added under continuously stirring for 5 minute, followed by last degassing. The composites were cured at room temperature, in rubber molds with samples dimension of $\Phi 6 \times 6 \mathrm{~mm} \times \mathrm{mm}$, for compression test. The composite samples were further heated in an oven, at $70^{\circ} \mathrm{C}$, for 8 hours.

\section{Compression and bending tests}

Bending samples were prepared in rubber molds with dimensions $40 \mathrm{~mm}$ x $8 \mathrm{~mm}$ x $4 \mathrm{~mm}$. Compression and three point bending tests were performed according to ISO 604 and ISO 178, respectively, using an INSTRON 8872 Servohydraulic Fatigue Testing System (Fig.1a). The compression samples were tested at a crosshead speed of $1 \mathrm{~mm} / \mathrm{min}, 5 \mathrm{~mm} / \mathrm{min}, 10$ $\mathrm{mm} / \mathrm{min}, 25 \mathrm{~mm} / \mathrm{min}$ and $50 \mathrm{~mm} / \mathrm{min}$. Five tests of each type of composites were conducted.

\section{Differential Scanning Calorimetry (DSC)}

The test was performed according to the ASTM 1269 standard, using DSC equipment from Mettler Toledo (Fig. 1b). The samples were maintained at $30^{\circ} \mathrm{C}$ for 3 minutes, then they were heated from $30^{\circ} \mathrm{C}$ to $90^{\circ} \mathrm{C}$ with heating rate of $10^{\circ} \mathrm{C} / \mathrm{min}$, maintained for 3 minutes at $90^{\circ} \mathrm{C}$ and cooled from $90^{\circ} \mathrm{C}$ to $30^{\circ} \mathrm{C}$ with cooling rate of $10^{\circ} \mathrm{C} / \mathrm{min}$. The mass of samples was of 31 $\mathrm{mg}$. Five samples of each material were used for measurements. The glass transition was evaluated from the second run to erase the thermal history of the sample.

\section{Thermo-mechanical analysis (TMA)}

Thermo-mechanical analysis (TMA) was conducted according to ASTM E831 using a TMA/ SDTA 840 equipment from Mettler Toledo (Fig. 1c). Coefficient of thermal expansion (CTE) was measured on specimens of nominal dimensions of $8 \times 10 \times 2 \mathrm{~mm}$. Five specimens of each material were tested for CTE. The temperature range was $30^{\circ} \mathrm{C}-220^{\circ} \mathrm{C}$ at a constant rate of $10^{\circ} \mathrm{C} / \mathrm{min}$ and the modification of the specimen width was recorded.

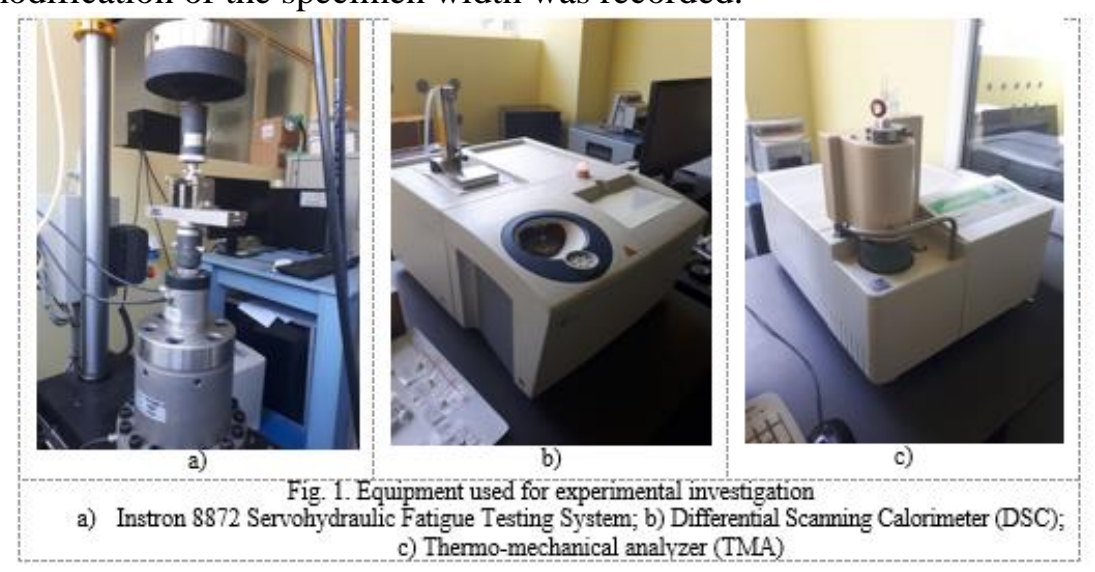




\section{Results and discussions}

\section{Compression test}

A typical compression response of the tested MWCNT/ vinyl ester and SWCNT/ vinyl ester is shown in Fig.2. Results from Fig. 2 clearly indicate that there is no significant variation in compression stress between the composites and vinyl ester. It can be seen that the compressive stress of vinyl ester and its carbon nanotubes composites significantly increase with increasing test speed, as presented in Fig. 2. The MW 0.1 featured the best compression properties among the three nanocomposites considered. Very little improvement was observed when stress is increased by $11 \mathrm{MPa}(8 \%)$ for MW 0.1 under test speed of $10 \mathrm{~mm} / \mathrm{min}$ and $25 \mathrm{~mm} / \mathrm{min}$ (Fig.2a). Upon incorporation of only $0.15 \mathrm{wt}$. \% SWNTs, the compression stress of vinyl ester is significantly improved by about $14 \%$ from 135 to $155 \mathrm{MPa}$, in case of test performed at a speed of 5 $\mathrm{mm} / \mathrm{min}$ (Fig.2b). Moreover, it is worth comparing the mechanical properties of MWCNT/ vinyl ester with SWCNT/ vinyl ester nanocomposites studied here. Upon reaching the test speed of $5 \mathrm{~mm} / \mathrm{min}$, SWCNT / vinyl ester takes the higher value of compression stress. If the test speed increases above $5 \mathrm{~mm} / \mathrm{min}$, the influence of MWCNT on compression stress become more pronounced (Fig.2c). The gap between SW 0.15 and MW 0.15 increases from $6 \%$ up to 13\% in case of a test speed of $5 \mathrm{~mm} / \mathrm{min}$. With the exception of the nanocomposites MW 0.2 and SW 0.2, it can be noticed that the compression stress has improved, compared to the neat vinyl ester resin.

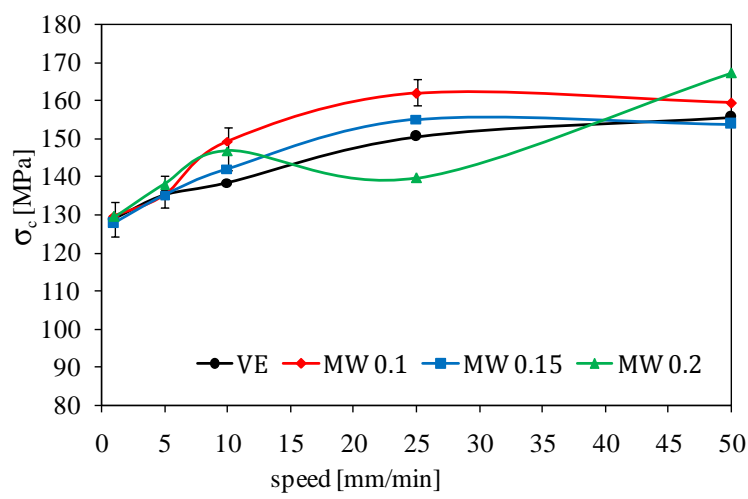

$\mathrm{a}$

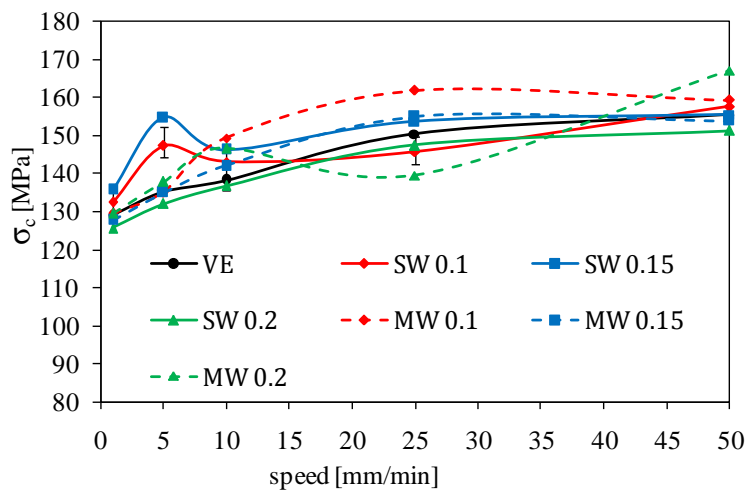

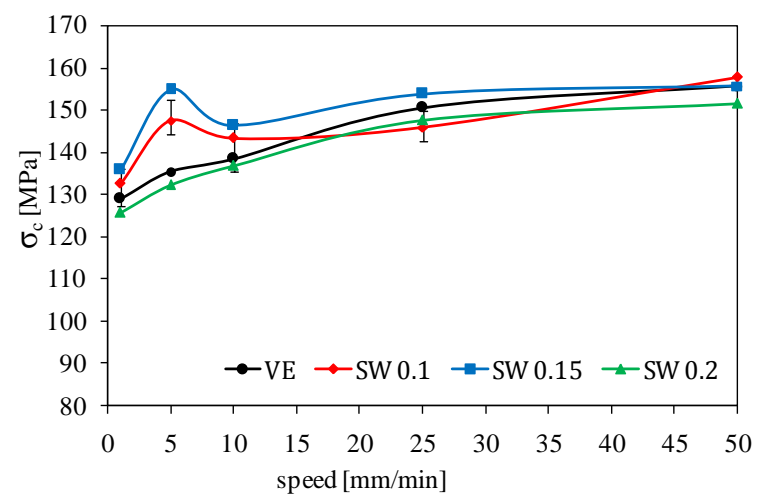

b

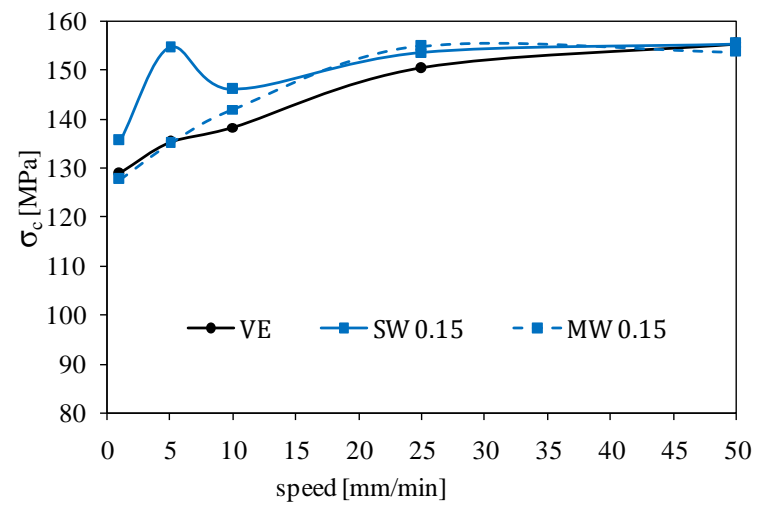

$\mathrm{c}$

d

Fig.2. Compression stress vs. test speed for: a) VE, MW; b)VE, SW; c) VE, MW, SW; d) VE, SW 0.15, MW 0.15

Figure 3 shows the compression modulus as a function of test speed. In general, all materials exhibit an increasing compression modulus when test speed increases. The $0.15 \mathrm{wt} \%$ MWCNT/vinyl ester composite exhibits higher compression modulus than the other MWCNT/ vinyl ester composites and neat vinyl ester until test speed reaches 5 $\mathrm{mm} / \mathrm{min}$. Continuing to increase test speed, MW 0.1 shows higher compression modulus than other nanocomposites, suggesting that small quantities of MWCNTs improve the compression modulus of the vinyl ester matrix (Fig.3.a). The MW 0.1 exhibits the highest compression modulus among all of the MWCNT/ vinyl ester composite samples. Compared to neat vinyl ester, the compression modulus of MW 0.1 is increased by $16 \%$ in tests performed with $25 \mathrm{~mm} / \mathrm{min}$. The addition of MWCNTs improved the compression modulus of vinyl ester in 11 tests from 15 performed. Fig.3.b illustrates the effect of SWCNTs on the compression modulus of vinyl ester composites. As observed in Fig. 3.b, SWCNTs have a 
significant effect on compression modulus and SW 0.15 yielded a better compression modulus when compared to neat vinyl ester resin until the test speed reached $25 \mathrm{~mm} / \mathrm{min}$. After that speed, vinyl ester resin showed a higher compression modulus than SWCNT/ vinyl ester nanocomposites. The compression modulus of SW 0.15 is seen to increase by up to $9 \%$ compared to neat vinyl ester, for tests speed of $10 \mathrm{~mm} / \mathrm{min}$. Overall, SWCNT/vinyl ester increased compression modulus of vinyl ester in 10 tests from 15 performed. Fig.3.c, d illustrates the visible effect of MWCNTs compared to SWCNTs in improvement of compression modulus of vinyl ester. At the same content, MW 0.1 showed a higher compression modulus compared to SW 0.1, after the tests performed at test speed over $10 \mathrm{~mm} / \mathrm{min}$. Compression test using different speeds shows that incorporation of a small amount of carbon nanotubes of about $0.2 \mathrm{wt}$. \% into vinyl ester resin can slightly improve the compression modulus and compression stress by about $11 \%$ and $14 \%$, respectively. It is thus believed that the strong interfacial adhesion between carbon nanotubes and vinyl ester resin is responsible for the significant improvement of mechanical property as shown in Fig.2-3.

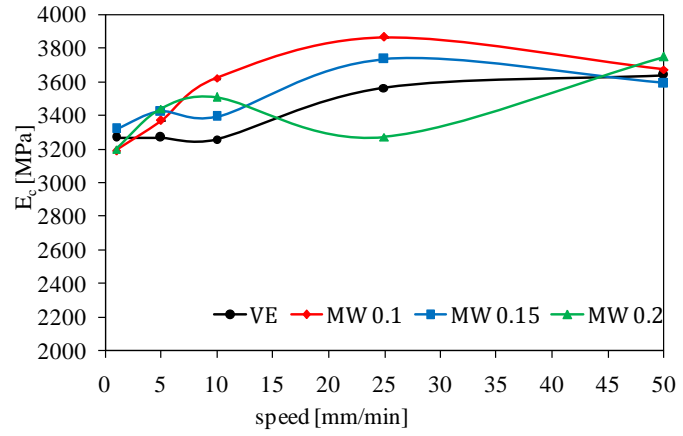

a



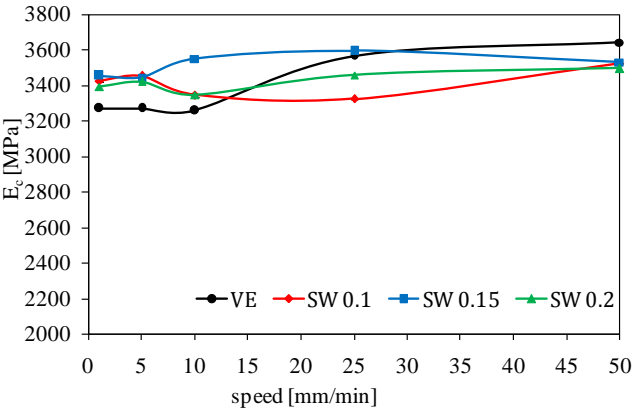

b

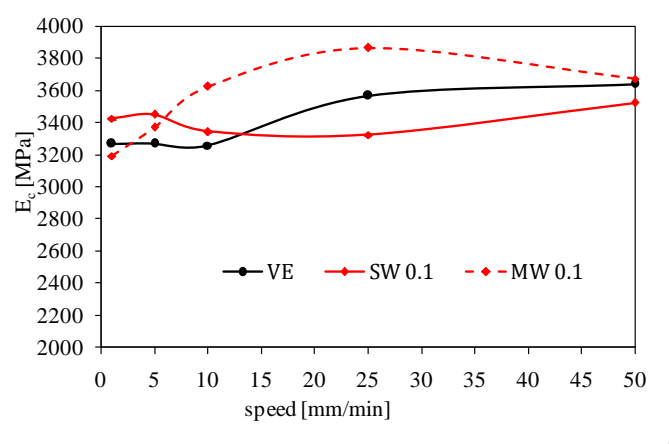

Fig.3. Compression modulus vs. test speed for: a) VE, MW; b)VE, SW; c) VE, SW and MW; d) VE, SW 0.2 and MW 0.2

\section{Bending test}

Figure $4 \mathrm{a}$, b shows a comparison of the bending stress recorded for three nanocomposites and the vinyl ester resin. As shown in the Fig.4a, MW0.2 nanocomposite exhibits the highest bending stress compared to MW 0.1, MW 0.15 and VE. Addition of MWCNTs has improved the bending stress of vinyl ester resin in 10 test from 15 performed. For SWCNT/ vinyl ester composites, as shown in Fig.4b, SW 0.1 exhibited better bending stress than SW 0.15, SW 0.2 and VE. It can be clearly seen that bending stress of the SW 0.1 is nearly 2.3 times higher than neat vinyl ester for the test performed with $10 \mathrm{~mm} / \mathrm{min}$. This may be due to the efficient load transfer between the SWCNTs and vinyl ester matrix. An overall estimation revealed that addition of MWCNTs and SWCNTs into vinyl ester matrix improved the bending stress, in all the cases. For the same content of additive, SWCNTs had a higher influence on the bending stress of vinyl ester resin than MWCNT. Fig.4d shows the bending stress of 0.1 wt. \% SWCNT and $0.1 \mathrm{wt}$. \% MWCNT/ vinyl ester composites. SW 0.1 showed a higher bending stress than MW 0.1 for tests speed higher than $5 \mathrm{~mm} / \mathrm{min}$. The bending stress of SW $0.1 \mathrm{reaches}$ the maxim of $81.5 \mathrm{MPa}$ for test conducted with $10 \mathrm{~mm} / \mathrm{min}$, and increases by $25 \%$ to $56 \%$ in comparison with MW 0.1 . 


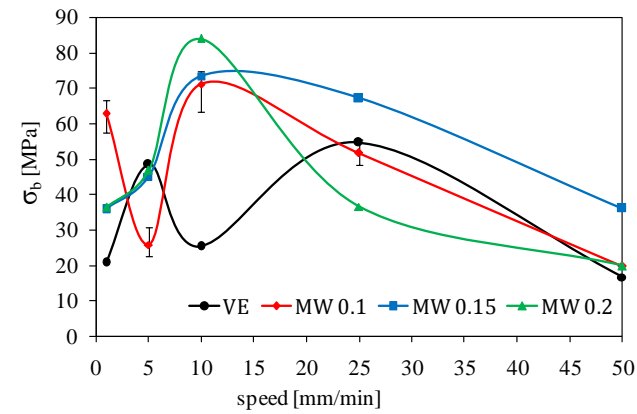

a

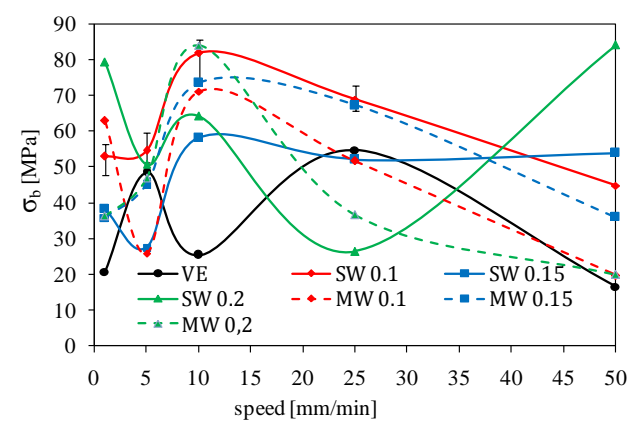

c

Fig.4. Bending stress vs. test speed for: a) VE, MW; b)VE, SW; c) VE, SW, MW; d) VE, MW 0.1, SW 0.1

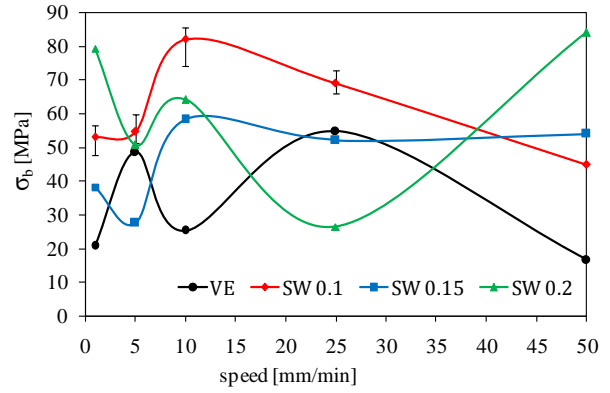

b

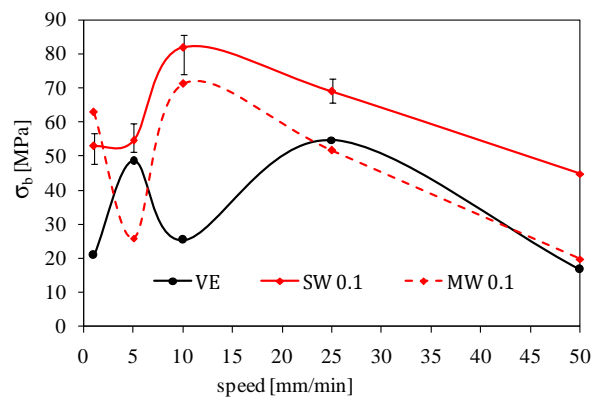

d

Fig.5 shows bending modulus as a function of tests speed for SWCNT and MWCNT/ vinyl ester nanocomposite. In all tests, the bending modulus of MWCNT/ vinyl ester composites exhibits a higher value than neat vinyl ester (Fig.5a). The bending modulus of vinyl ester was improved by $26 \%, 47 \%$ and $27 \%$, respectively, for tests performed with $1 \mathrm{~mm} / \mathrm{min}, 5$ $\mathrm{mm} / \mathrm{min}$ and $25 \mathrm{~mm} / \mathrm{min}$, in case of MW 0.1. Fig.5b shows the bending modulus variation of nanocomposites SW 0.1 , SW 0.15 , SW 0.2 and neat vinyl ester. In case of SW 0.1 nanocomposite, the bending modulus value increases by $33 \%$ and $45 \%$, respectively, for test speeds of $1 \mathrm{~mm} / \mathrm{min}$ and $5 \mathrm{~mm} / \mathrm{min}$ (Fig. 5c). A careful examination of results reveals that MWCNTs have a strong effect on flexural modulus of vinyl ester than SWCNTs (Fig.5d).

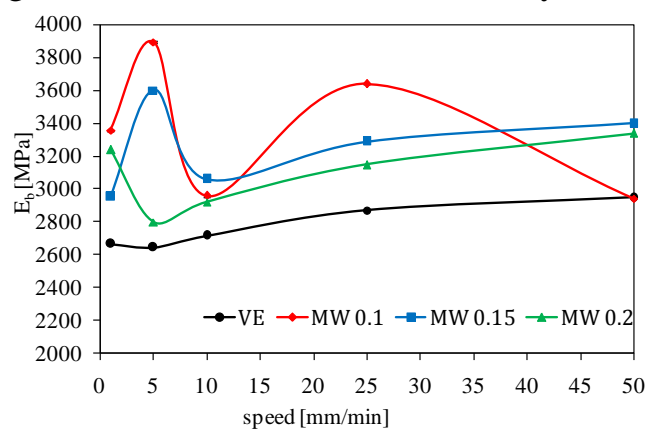

a

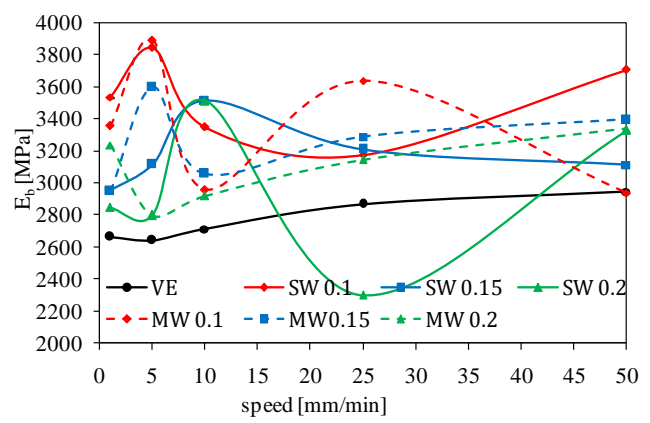

$\mathrm{c}$

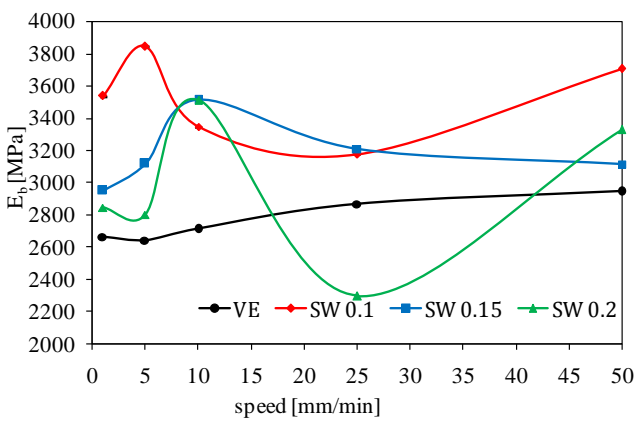

b

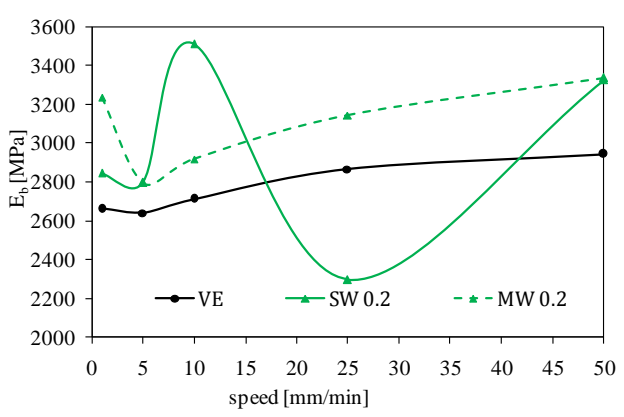

$\mathrm{d}$ 
Adding CNTs into vinyl ester resin leads to mechanical properties improvement for all the nanocomposites being tested. The presence of MWCNTs and SWCNTs may hinder the mobility of polymer chains, during the curing reaction, as well as modifying the final structure of cross-linked network of the vinyl ester resin. The strengthening of interfacial bonding between the vinyl ester matrix and carbon nanotubes enables an effective transfer of internal stresses between vinyl ester and CNTs, leading to the enhancement of the mechanical properties of CNTs/vinyl ester nanocomposites.

\section{Differential Scanning Calorimetry (DSC)}

DSC analysis for both SWCNT and MWCNT / vinyl ester composites was performed for all types of samples investigated. Fig.6 shows DSC thermograms of SWCNT and MWCNT/ vinyl ester composites. Results demonstrate the increase in specific heat for MW and SW nanocomposites compared to neat vinyl ester. DCS graphs reveal that, in case of MW 0.15 and SW 0.15 , the specific heat takes higher values along the temperature range. Furthermore, DSC thermograms highlight an endothermic melting process with peak temperatures between $80^{\circ}-90^{\circ} \mathrm{C}$.

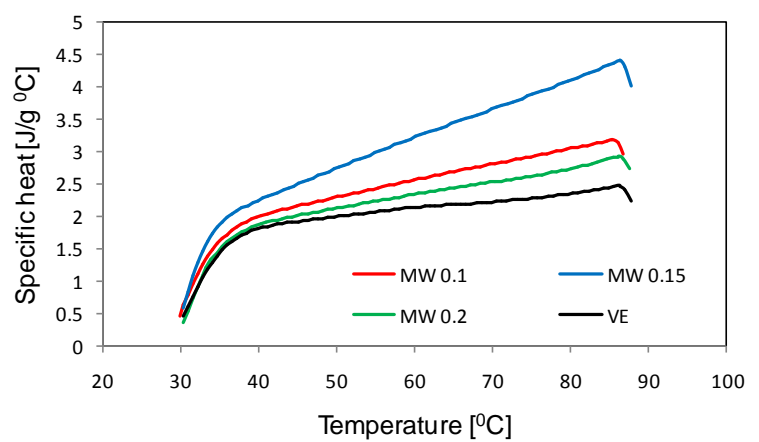

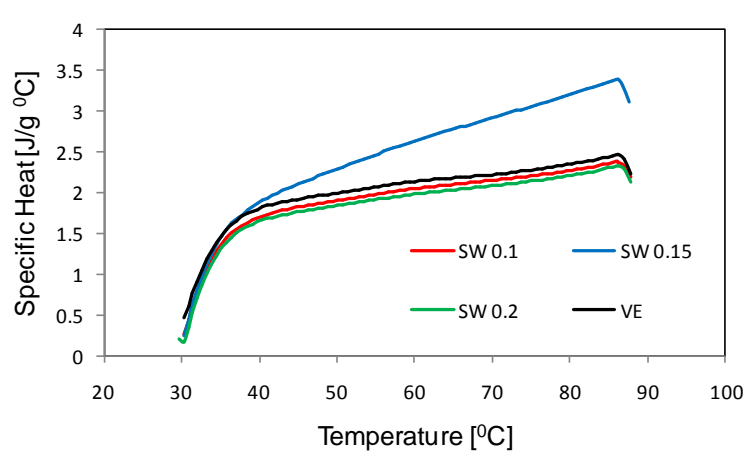

b

Fig.6. Specific heat vs. temperature for: a) VE and MW; b) VE and SW

DSC results clearly suggest the good thermal stability of SWCNT and MWCNT/ vinyl ester nanocomposites. It was observed that the glass transition temperature ( $\mathrm{Tg}$ ) increased with addition of CNTs, due to the restriction in polymer chain mobility caused by interaction with carbon nanotubes. The increase in Tg of CNT/ vinyl ester nanocomposites was explained by the prevention of the motion of the vinyl ester macromolecular chains due to the presence of the carbon nanotubes. For contents above $0.15 \%$, the $\mathrm{Tg}$ is found to decrease due to the formation of nanoparticles agglomerates which are not very effective in the restriction of chain mobility. Glass transition temperature increases from $91.1^{\circ} \mathrm{C}$ for neat vinyl ester to $96.3^{\circ} \mathrm{C}$ for $0.15 \mathrm{wt}$ \% SWCNT/ vinyl ester and to $97.91^{\circ} \mathrm{C}$ for $0.15 \mathrm{wt} . \% \mathrm{MWCNT} /$ vinyl ester.

\section{Thermo-mechanical analysis (TMA)}

The thermal expansion coefficient below and above glass transition temperature of neat vinyl ester and its nanocomposites was calculated from the slopes of thermograms using STAR ${ }^{\mathrm{e}}$ software. Resulted values are given in Table 1 for three temperature ranges $\left(30^{\circ}-80^{\circ} \mathrm{C}, 30^{\circ}-220^{\circ} \mathrm{C}\right.$ and $\left.100^{\circ}-220^{\circ} \mathrm{C}\right)$. It is clear that the $\mathrm{CTE}$ decreases with the content of carbon nanotubes in all cases. The addition of 0.15 and $0.2 \mathrm{wt} . \%$ of MWCNTs produces the higher decrease in CTE below $\mathrm{Tg}$ (in this case the fall was about $11.9 \%$ ). In temperature range above Tg, SW 0.1 and SW 0.15 recorded the lower CTE, by a diminution of $17.8 \%$. Furthermore, there is no direct ratio between CNTs type, CNTs content and CTE values. That may be explained by admitting the existence of an optimal threshold for carbon nanotubes content into vinyl ester resin, taking into account that carbon nanotubes tend to agglomerate thus affecting the dispersion process during samples formation.

As for glass transition temperature, it can be noticed that $\mathrm{Tg}$ increases as the carbon nanotubes are being incorporated into the vinyl ester composites. Tg was higher than those of vinyl ester resin for 0.1 and $0.15 \mathrm{wt}$. \% content of carbon nanotubes. An increasing of $\mathrm{Tg}$, with $5^{\circ} \mathrm{C}$ and $6^{\circ} \mathrm{C}$, was measured for SW 0.15 and MW 0.15 .

In Table 2, the Tg values, as determined by TMA and DSC methods, are shown. It is worth noting that Table 2 reveals significant difference between glass transition temperature measured by DSC and TMA which may be due to the use of two different measurement methods and the instrument sensitivity. 
Table 1

CTE FOR SWCNT AND MWCNT/ VINYL ESTER NANOCOMPOSITES

\begin{tabular}{lccc}
$\begin{array}{l}\text { Temperature } \\
\text { range } \rightarrow\end{array}$ & $30^{\circ}-80^{\circ} \mathrm{C}$ & $30^{\circ}-220^{\circ} \mathrm{C}$ & $100^{\circ}-220^{\circ} \mathrm{C}$ \\
\hline Samples $\downarrow$ & Coefficient of thermal expansion $(\mathrm{CTE})$ \\
\multicolumn{4}{c}{$\left[\mu \mathrm{m} /\left(\mathrm{m} \times{ }^{\circ} \mathrm{C}\right)\right]$} \\
\hline VE & 84.02 & 122.03 & 191.41 \\
SW 0.10 & 75.77 & 117.93 & 182.76 \\
SW 0.15 & 82.36 & 138.67 & 157.86 \\
SW 0.20 & 84.17 & 116.81 & 158.68 \\
MW 0.10 & 81.03 & 52.76 & 182.82 \\
MW 0.15 & 74.57 & 80.78 & 188.03 \\
MW 0.20 & 74.17 & 89.55 & 177.57
\end{tabular}

Table 2

\begin{tabular}{|c|c|c|}
\hline Method $\rightarrow$ & TMA & DSC \\
\hline Samples $\downarrow$ & \multicolumn{2}{|c|}{$\begin{array}{c}\text { Glass transition temperature } \\
(\mathrm{Tg})\left[{ }^{\circ} \mathrm{C}\right]\end{array}$} \\
\hline VE & 91.11 & 81.12 \\
\hline SW 0.10 & 96.30 & 84.30 \\
\hline SW 0.15 & 96.01 & 83.10 \\
\hline SW 0.20 & 84.30 & 80.34 \\
\hline MW 0.10 & 95.77 & 82.31 \\
\hline MW 0.15 & 97.91 & 84.42 \\
\hline MW 0.20 & 84.87 & 82.19 \\
\hline
\end{tabular}

\section{SEM Images}

Carbon nanotubes, particularly the functionalized ones, have the ability to form a network throughout the polymer matrix. When the content of CNTs is higher, the network formed in the matrix is more developed. Content close to the percolation threshold has a beneficial effect on the physical properties of the composites. Thus, the thermal conductivity, the dimensional stability and the mechanical strength are improved. Figure 7 suggests the presence of carbon nanotubes into vinyl ester matrix of the nanocomposites. SEM images were obtained on fracture surface of CNT/vinyl ester samples, after bending tests. As seen in Figure 7d, a proper dispersion of the carbon nanotubes within the polymer resin was achieved. Also, SEM analysis reveals the dimensions of CNTs diameters, which are different for MWCNTs and SWCNTs, i.e. around $100 \mathrm{~nm}$ and $50 \mathrm{~nm}$, respectively (Fig. 7a and 7c, for $0.1 \mathrm{wt}$. \% content), or about $60 \mathrm{~nm}$ and $30 \mathrm{~nm}$, respectively, for $0.2 \mathrm{wt}$. $\%$ content (Fig. $7 \mathrm{~b}$ and $7 \mathrm{~d}$ ).

A well-defined and homogeneous SWCNTs network can be seen in Figure 7d. Certainly, this relatively dense and uniform CNTs network ensures a reinforcement of the composite material and an improvement of the thermal conductivity and dimensional stability. 


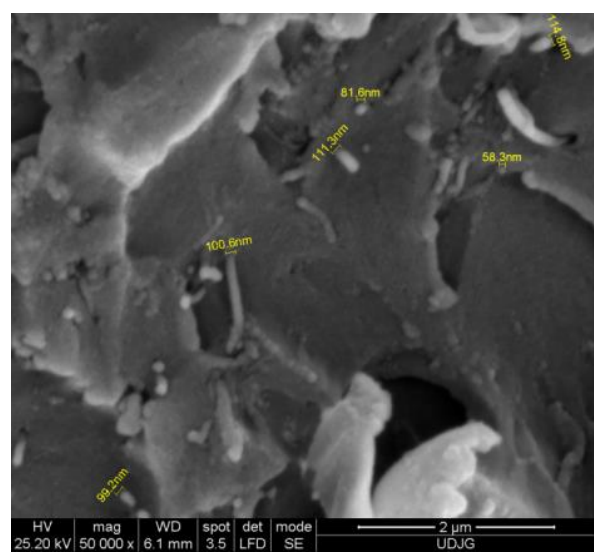

a)

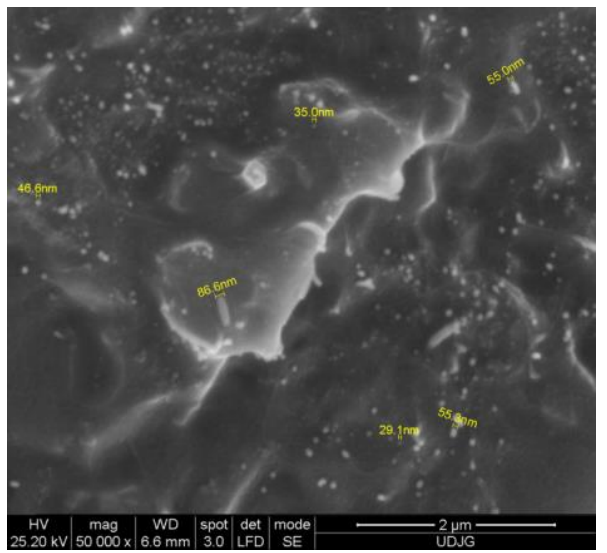

c)

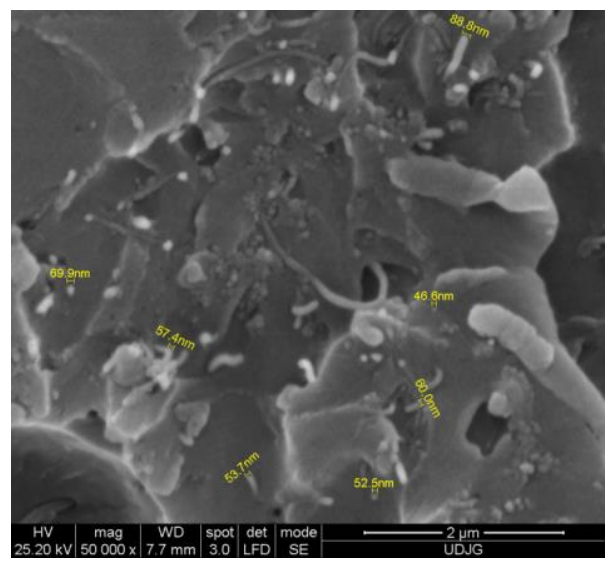

b)

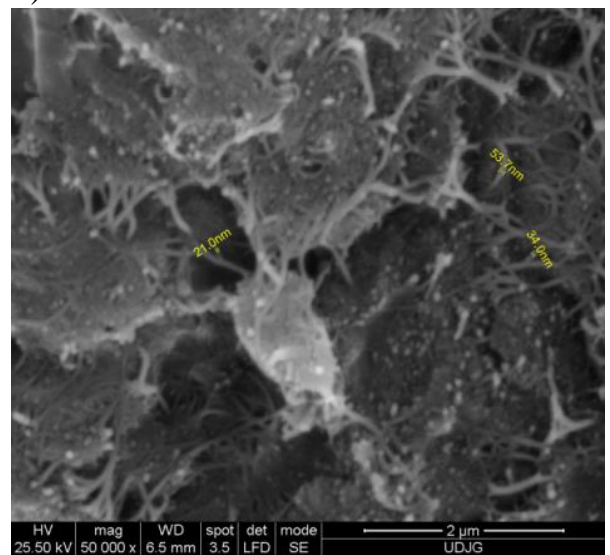

d)

Fig.7. SEM images of fractured nanocomposite samples: a) MW 0.1; b) MW 0.2 ; c) SW 0.1 ; d) SW 0.2

\section{Conclusions}

The mechanical and thermal properties of SWCNT and MWCNT/ vinyl ester nanocomposites have been studied. Compression, three point bending test, differential scanning calorimetry and thermo-mechanical analysis were performed over nanocomposite samples. In case of SW 0.15 composite, a maximum increase of $14 \%$ and $9 \%$, respectively, for compression strength and elastic modulus have been noticed, as compared to the vinyl ester resin. After bending test of MW 0.1 and SW 0.1 nanocomposites, a maximum increase of $47 \%$ and $46 \%$, respectively, have been obtained for elastic modulus and bending strength, as compared to the neat resin. In case of compression tests performed at speed up to 5 $\mathrm{mm} / \mathrm{min}$, SWCNTs induced better mechanical behavior of the nanocomposites than MWCNTs. As for MW 0.15 and MW0.2 nanocomposites, the coefficient of thermal expansion has shown a decrease of about $12 \%$ as compared to neat vinyl ester resin. Enhancement of mechanical and thermal properties of CNTs/ vinyl ester nanocomposites is due to the proper dispersion and interfacial interaction between MWCNTs and vinyl ester resin. Addition of carbon nanotubes into vinyl ester resin lead to structural changes of the nanocomposite. Thus, the increase in compression strength, elastic modulus, specific heat, glass transition temperature and coefficient of thermal expansion may be accounted for by the excellent mechanical and thermal properties of carbon nanotubes introduced into the vinyl ester nanocomposites.

Acknowledgement: The work has been funded by the Sectorial Operational Programme Human Resources Development 2007-2013 of the Ministry of European Funds through the Financial Agreement POSDRU/159/1.5/S/132397 ExcelDOC.

\section{References}

1.LA SCALA, J.J., LOGAN, M.S., SANDS, J.M., PALMESE, G.R., Compos. Sci. Technol., 68, 2008, p. 1869.

2.SULTANIA, M., YADAW, S.B., RAI, J.S.P., SRIVASTAVA, D., Mater. Sci. Eng.: A, 527, 2010, p. 4560.

3.SOUSA, J.M., CORREIA, J.R., CABRAL-FONSECA, S., DIOGO, A.C., Compos. Struct.,116, 2014, p. 720.

4.DREERMAN, E., NARKIS, M., SIEGMANN, A., JOSEPH, R., DODIUK, H., DiBENEDETTO, A.T., J. Appl. Polym. Sci.,72, 1999 , p. 647.

5.ATTA, A.M., EL-SAEED, S.M., FARAG, R.K., React. Funct. Polym.,66, 2006, p. 1596.

6.JASWAL, S., GAUR, B., Rev. Chem. Eng.,30, 2014, p. 567.

7.TEKALUR, S.A., SHIVAKUMAR, K., SHUKLA, A., Compos. Part B Eng.,39, 2008, p. 57. 
8.GUPTA, N., YE, R., PORFIRI, M., Compos. Part B Eng.,41, 2010, p. 236.

9.RAY, D., SENGUPTA, S., SENGUPTA, S.P., MOHANTY, A.K., MISRA, M., Macromol. Mater. Eng., 291, 2006, p. 1513.

10.LIN, L.Y., LEE, J.H., HONG, C.E., YOO, G.H., ADVANI, S.G., Compos. Sci. Technol.,66, 2006, p.2116.

11 RAGHAVENDRA, N., NARASIMHA MURTHY, H. N., KRISHNA, M., VISHNU MAHESH, K. R., SRIDHAR, R., FIRDOSH, S., ANGADI, G., SHARMA, S.C., Front.Mater. Sci., 7, 2013, p. 396.

12.SRIDHAR, R., NARASIMHA MURTHY, H.N., PATTAR, N., VISHNU MAHES, K.R., KRISHNA, M., Compos. Part B Eng., 43,2012 , p. 599. 13.RAGHAVENDRA, N., NARASIMHA MURTHY, H. N., VISHNU MAHESH, K. R., MYLARAPPA, M., ASHIK, K.P., SIDDESWARA, D.M.K., KRISHNA, M., Mater. Today Proc.,4, 2017, p.12109.

14.JI, G., LI, G., Mater. Sci. Eng. A, 498, 2008, p. 327.

15.RATNA, D., KHAN, S., BARMAN, S., CHAKRABORTY, B.C., Open Macromol. J.,6, 2012, p. 59.

16.ALHUTHALI, A., LOW, I.M., DONG, C., Compos. Part B Eng.,43, 2012, p. 2772.

17.ALATEYAH, I. , DHAKAL, H. N., ZHANG, Z.Y., Polym. Plast. Technol.,53, 2014, p. 327.

18.JAILLET, F., NOUAILHAS, H., BOUTEVIN, B., CAILLOL, S., Eur. Polym. J.,71, 2015, p. 248.

19.SULTANIA, M., RAI, J.S.P., SRIVASTAVA, D., Eur. Polym. J.,46, 2010, p. 2019.

20. KARGER-KOCSIS, J., GRYSHCHUK, O., FRÖHLICH, J., MÜLHAUPT, R., Compos. Sci. Technol., 63, 2003 , p. 2045.

21.MAITY, T., SAMANTA, B.C., DALAI, S., BANTHIA, A.K., Mater. Sci. Eng. A,464, 2007, p. 38.

22.OMRANI, A., SIMON, L.C., ROSTAMI, A.A., Mater. Chem. Phys.,114, 2009, p.145.

23.EHSANI, M., KHONAKDAR, H.A., GHADAMI, A., Prog. Org. Coatings, 76, 2013, p. 238.

24.JAVAID, U., KHAN, Z.M., KHAN, M.B., BASSYOUNI, M., Compos. Part B Eng.,91, 2016, p. 257.

25.XU, L.R., KRISHNAN, A., NING, H., VAIDYA, U., Compos. Part B Eng.,43, 2012, p. 2480.

26.WONDERLY, C., GRENESTEDT, J., FERNLUND, G., CĚPUS, E., Compos. Part B Eng.,36, 2005, p. 417.

27.LAOUBI, K., HAMADI, Z., AHMED BENYAHIA, A., SERIER, A., AZARI, Z., Compos. Part B Eng.,56, 2014 , p. 520.

28.SILVESTRE, N., Int. J. Solids Struct.,45, 2008, p. 4902.

29.GARG, M., PANTANO, A., BOYCE, M.C., J. Eng. Mater. Technol.,129, 2007, p. 431.

30.NISHIMURA, M., TAKAHASHI, N., TAKAGI, Y., Comput. Mater. Sci.,130, 2017, p. 214.

31.RAFIEE, R., MOGHADAM, R.M., Compos. Part B Eng.,56, 2014, p. 435.

32.WANG, Q., LIEW, K.M., HE, X.Q., XIANG, Y., Appl. Phys. Lett.,91, 2007, 093128.

33.LI, X., YANG, W., LIU, B., Phys. Rev. Lett.,98, 2007, 205502.

34. CAO, G., CHEN, X., Phys. Rev. B,73, 2006, 155435.

35. ANDREI, G., DIMA, D., BIRSAN,I., ANDREI, L., CIRCIUMARU, A., Mat. Plast., 46, 2009, p. 284.

36. CIRCIUMARU, A., ANDREI, G., BIRSAN,I., SEMENESCU, A., Mat. Plast., 46, 2009, p. 211.

37. DIMA, D., ANDREI, G., Materialwiss. Werkst., 34, 2003, p.349.

38. GUPTA, S.S., AGRAWAL, P., BATRA, R.C., J. Appl. Phys.,119, 2016, 245106

39. LIAO, S., YEN, C., WENG, C., LIN, Y., et al., J. Power Sources, 185, 2008, p.1225.

40. FAN, Z., HSIAO, K.-T., ADVANI, S.G., CARBON N. Y.,42, 2004, p. 871.

41. LIAO, W.H., TIEN, H.W., HSIAO, S.T., LI, S.M., ACS Appl. Mater. Interfaces,5, 2013, p. 3975.

42. YURDAKUL, H., SEYHAN, A.T., TURAN, S., TANOĜLU, M., Compos. Sci. Technol.,70, 2010, p. 2102.

43. GRYSHCHUK, O., KARGER-KOCSIS, J., THOMANN, R., KÓNYA, Z., KIRICSI, I., Compos. Part A Appl. Sci. Manuf.,37, 2006, p. 1252.

44. MURARESCU, M., DIMA, D., ANDREI, L., CIRCIUMARU, A., Dig J Nanomater. Biostructures, 9, 2014 , p. 653.

45. CIUPAGEA, L., ANDREI, G., DIMA, D., MURARESCU, M., Dig J Nanomater. Biostructures, 8, 2013 , p.611.

Manuscript received: 25.09 .2019 